Original Contribution

\title{
SOME EMPIRICAL CORRELATIONS BETWEEN THE THERMODYNAMIC PROPERTIES OF HYDROGEN CYANIDE, WATER AND ACETYLENE MOLECULES AND THEIR INFRARED SPECTRA
}

\author{
A. T. Atanasov* \\ Department of Physics and Biophysics, Medical Faculty, Trakia University, Bulgaria
}

\begin{abstract}
A new method for calculating vibrational modes in the infrared region of the spectrum is proposed. The method is based on the thermodynamic parameters of the molecules- standard molar Gibbs free energy change of molecular formation $\Delta \mathrm{G}_{\mathrm{f}}^{0}(\mathrm{~kJ} / \mathrm{mol})$, standard molar enthalpy change of molecular formation $\Delta \mathrm{H}_{\mathrm{f}}^{0}(\mathrm{~kJ} / \mathrm{mol})$ and standard molar entropy of molecule $\mathrm{S}^{0}(\mathrm{~J} / \mathrm{mol} \cdot \mathrm{K})$. From these thermodynamics parameters the vibrational modes can be calculated using $\mathrm{T}_{\mathrm{G}}=\Delta \mathrm{G}_{\mathrm{f}}^{0} / \mathrm{S}^{0}$ and $\mathrm{T}_{\mathrm{H}}=\Delta \mathrm{H}_{\mathrm{f}}^{0} / \mathrm{S}^{0}$ (in K) as 'apparent' temperatures. After equation of thermal energy $\mathrm{kT}_{\mathrm{G}}$ and $\mathrm{kT}_{\mathrm{H}}$ (where $\mathrm{k}$ is Boltzmann constant) to energy of electromagnetic quanta $\mathrm{hf}_{\mathrm{G}}$ and $\mathrm{hf}_{\mathrm{H}}$ (where $\mathrm{f}$ is frequency in $\mathrm{Hz}$ ), it can calculate the wavenumbers (in $\mathrm{cm}^{-1}$ ) of vibrational modes as: $\mathrm{kT}_{\mathrm{G}} / \mathrm{ch}$ and $\mathrm{kT}_{\mathrm{H}} / \mathrm{ch}$ (where $\mathrm{c}$ is the speed of light and $\mathrm{h}$ is the Planck constant).
\end{abstract}

Key words: IR spectrum, Gibbs free energy, enthalpy, entropy

\section{INTRODUCTION}

1. Main infrared regions. The molecules can vibrate in many ways, and each way is called a 'vibrational mode'. In terms of wavenumbers of vibrational modes the infrared spectral region spans from 33 to $12820 \mathrm{~cm}^{-1}$ [1, 2]. The entire infrared range is divided into 3 areas: near- infrared (12820-4000 $\left.\mathrm{cm}^{-1}\right)$, mid-infrared (4000-400 cm $\left.\mathrm{cm}^{-1}\right)$, far-infrared $\left(400-33 \mathrm{~cm}^{-}\right.$ $\left.{ }^{1}\right)$.The near- infrared region is poor in specific absorptions. Consist of overtones and combination bands resulting from vibrations in the mid-infrared region of the spectrum. The mid-infrared region provides structural information for most organic molecules. The far-infrared region has been less investigated than the other two regions. It has been used with inorganic molecules. The low energies of infrared quanta is not sufficient to cause electronic transitions but they are large enough to cause changes in the frequency and amplitude of molecular vibrations. Infrared spectra have been represented as percent of transmittance versus either the wavenumber of the wavelength. The use of wavenumbers (expressed in $\mathrm{cm}^{-1}$ ) is standard, with the use of wavelength (expressed in $\mathrm{nm}$ or $\mu \mathrm{m}$ ). On Figure $\mathbf{1}$ are given the main selected IR frequencies.

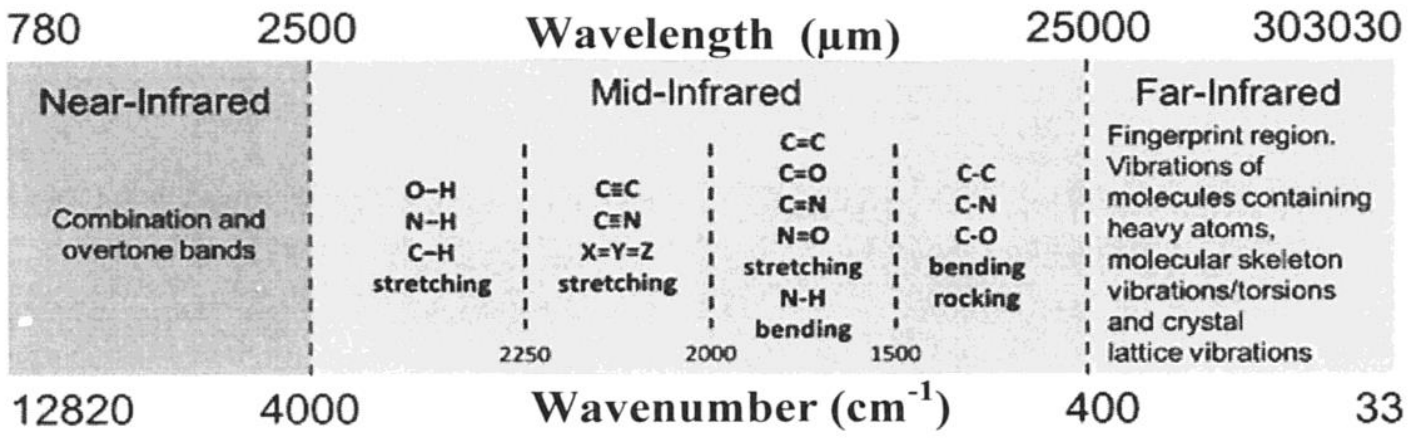

Figure 1. Main Infrared Regions

\footnotetext{
*Correspondence to: Atanas Todorov Atanasov,

Department of Physics and Biophysics,

Medical Faculty, Trakia University,

Bulgaria, E-mail: atanastod@abv.bg
} 
2. The classic method of calculating molecular vibrations. The calculation of infrared molecular vibrations $[1,2]$ is based on the force (spring) constants $(\mathrm{k})$ for the given bond, the 'reduced mass' $(\mu)$, and the speed of light (c). The stretching frequency $\left(\right.$ in $\mathrm{cm}^{-1}$ ) of given bond on Fig.1 can be calculated by formula:

$$
v=1 / 2 \pi \mathrm{c}[\mathrm{k} / \mu]^{1 / 2}=1 / 2 \pi \mathrm{c}\left[\mathrm{k}\left(\mathrm{m}_{1}+\mathrm{m}_{2}\right) / \mathrm{m}_{1} \mathrm{~m}_{2}\right]^{1 / 2}
$$

where the force constants (k) has defined values for single, double and triple bonds:

$\mathrm{k}=5 \times 10^{5}$ dyne/cm for 'single bond'

$\mathrm{k}=10 \times 10^{5}$ dyne/cm for 'double bond'

$\mathrm{k}=15 \times 10^{5} \mathrm{dyne} / \mathrm{cm}$ for 'triple bond'

The 'reduced mass' appears a combination between the mass of atoms of the bond:

$\mu=\mathrm{m}_{1} \mathrm{~m}_{2} / \mathrm{m}_{1}+\mathrm{m}$

The mass $m_{1}$ and $m_{2}$ of the chemical elements are calculated in 'grams' by formula:

$\mathrm{m}=\mathrm{A} / \mathrm{N}_{\mathrm{A}}$, grams

where $\mathrm{A}=$ Atomic mass of given chemical element and $\mathrm{N}_{\mathrm{A}}=6.02 \times 10^{23}$ is Avogadro's number per $1 \mathrm{~g}-\mathrm{mol}$. The speed of light is taken as: $\mathrm{c}=3 \times 10^{10} \mathrm{~cm} / \mathrm{sec}$.

The different multiple mods can be obtained from the basic frequencies as multiple of the vibrational quantum number $n+1 / 2$, where $n=0$, $1,2,3 \ldots$ and so on.

\section{The proposed new thermodynamic} method for calculating molecular vibration.

The free energy $\Delta \mathrm{F}$, the enthalpy $\Delta \mathrm{H}$ and the entropy $\Delta S$ of each molecule at constant pressure and temperature are connected by Gibbs equation [3]:

$\Delta \mathrm{G}=\Delta \mathrm{H}-\mathrm{T} \Delta \mathrm{S}$

where $\mathrm{T}$ is the absolute temperature of the reaction of molecule formation. The Eq. 4 can be transformed as:

$$
\Delta \mathrm{G} / \Delta \mathrm{S}=\Delta \mathrm{H} / \Delta \mathrm{S}-\mathrm{T}
$$

The dimension of temperature of molecular formation ( $\mathrm{T}$ and ratios $\Delta \mathrm{G} / \Delta \mathrm{S}, \Delta \mathrm{H} / \Delta \mathrm{S}$ ) are same - dimension of absolute temperature $(\mathrm{K})$ on Kelvin scale. The same dimensions of $\mathrm{T}$, $\Delta \mathrm{G} / \Delta \mathrm{S}$ and $\Delta \mathrm{H} / \Delta \mathrm{S}$ ratio gives reason regard the ratio between the Gibbs free energy change $\Delta G$ and the entropy change $\Delta S$, as well as the ratio between the enthalpy change $\Delta H$ and the entropy change $\Delta \mathrm{S}$ as 'apparent' temperatures i.e.:

$\mathrm{T}_{\mathrm{G}}=\Delta \mathrm{G} / \Delta \mathrm{S}$

$\mathrm{T}_{\mathrm{H}}=\Delta \mathrm{H} / \Delta \mathrm{S}$

Because of the absolute temperature by Kelvin scale is always positive, we have to use the absolute (positive) values of $\mathrm{T}_{\mathrm{G}}$ and $\mathrm{T}_{\mathrm{H}}$ in all calculations.

The temperature of reaction $(\mathrm{T})$ and the 'apparent' temperature $\mathrm{T}_{\mathrm{G}}$ and $\mathrm{T}_{\mathrm{H}}$ corresponds to heat energies: $\mathrm{kT}, \mathrm{kT}_{\mathrm{G}}$ and $\mathrm{kT}_{\mathrm{H}}$, where $\mathrm{k}=$ $1.38 \times 10^{-23} \mathrm{~J} / \mathrm{K}$ is the Boltzmann constant.

These heat energies correspond to electromagnetic quanta $(\mathrm{hf}),\left(\mathrm{hf}_{\mathrm{G}}\right)$ and $\left(\mathrm{hf}_{\mathrm{H}}\right)$ with frequencies $\mathrm{f}(\mathrm{Hz}), \mathrm{f}_{\mathrm{G}}(\mathrm{Hz})$ and $\mathrm{f}_{\mathrm{H}}(\mathrm{Hz})$ and Planck constant $\mathrm{h}=6.6262 \times 10^{-34} \mathrm{~J} \cdot \mathrm{s}$ :

$\mathrm{hf}=\mathrm{kT}$

$\mathrm{hf}_{\mathrm{G}}=\mathrm{kT}_{\mathrm{G}}$

$\mathrm{hf}_{\mathrm{H}}=\mathrm{kT}_{\mathrm{H}}$

The $\mathrm{kT}_{\mathrm{G}}$ and $\mathrm{kT}_{\mathrm{H}}$ energies are connected to energy of chemical bonds and can be expected their corresponding frequencies match the frequencies of the absorption spectra of their molecules. From Eqns. (8-10) it can calculate the corresponding frequencies $\mathrm{f}, \mathrm{f}_{\mathrm{G}}$ and $\mathrm{f}_{\mathrm{H}}$ :

$\mathrm{f}=\mathrm{kT} / \mathrm{h}$

$\mathrm{f}_{\mathrm{G}}=\mathrm{kT}_{\mathrm{G}} / \mathrm{h}$

$\mathrm{f}_{\mathrm{H}}=\mathrm{kT}_{\mathrm{H}} / \mathrm{h}$

The frequency $\mathrm{f}(\mathrm{Hz})$ of the electromagnetic waves is connected to wavelength $\lambda(\mathrm{m})$ and speed of light $\mathrm{c}(\mathrm{m} / \mathrm{s})$ :

$\lambda=\mathrm{c} / \mathrm{f}$

From Eqns. (11-14) it can calculate the frequency expressed in wavenumbers $\left(\mathrm{v}, \mathrm{cm}^{-1}\right)$ by equation:

$v_{\mathrm{G}}=1 / \lambda=\mathrm{kT}_{\mathrm{G}} / \mathrm{ch}\left(\mathrm{cm}^{-1}\right)$

where $\mathrm{T}_{\mathrm{G}}=\Delta \mathrm{G} / \Delta \mathrm{S}$ (is taken in Kelvin degree), and respectively:

$v_{\mathrm{H}}=1 / \lambda=\mathrm{kT}_{\mathrm{H}} / \mathrm{ch}\left(\mathrm{cm}^{-1}\right)$

where $\mathrm{T}_{\mathrm{H}}=\Delta \mathrm{H} / \Delta \mathrm{S}$ (is taken in Kelvin degree).

Analogically, in the case of simple molecules, the data for standard Gibbs free energy change of molecular formation $\Delta \mathrm{G}_{\mathrm{f}}^{0}(\mathrm{~kJ} / \mathrm{mol})$, standard molar enthalpy change of molecular formation $\Delta \mathrm{H}_{\mathrm{f}}^{0}(\mathrm{~kJ} / \mathrm{mol})$, and standard molar entropy of molecule $S^{0}(\mathrm{~J} / \mathrm{mol} \cdot \mathrm{K})$ is need to use for calculation the 'apparent' temperature and the corresponding frequencies. The indicative survey showed that calculated by this way wavenumbers overlap with real infrared modes of the molecules.

\section{AIM OF THE STUDY}

1. To calculate the molecular vibrational modes of hydrogen cyanide $(\mathrm{HCN})$, water $\left(\mathrm{H}_{2} \mathrm{O}\right)$ and acetylene $\left(\mathrm{C}_{2} \mathrm{H}_{2}\right)$ molecules in infrared region by classical method and by proposed new thermodynamic method. 
2. To compare results from calculations with experimentally received spectra of the $\mathrm{HCN}, \mathrm{H}_{2} \mathrm{O}$ and $\mathrm{C}_{2} \mathrm{H}_{2}$ molecules.

\section{MATERIALS AND METHODS}

1. The molecule of $\mathrm{HCN}, \mathrm{H}_{2} \mathrm{O}$ and $\mathrm{C}_{2} \mathrm{H}_{2}$ were investigated.

2. The thermodynamic data for Standard molar Gibbs free energy change of molecular formation at $\Delta \mathrm{G}_{\mathrm{f}}^{0}(\mathrm{~kJ} / \mathrm{mol})$, Standard molar enthalpy change of
ATANASOV A. T. molecular formation $\Delta \mathrm{H}_{\mathrm{f}}{ }^{0}(\mathrm{~kJ} / \mathrm{mol})$ and Standard molar entropy of molecule $\mathrm{S}^{0}$ $(\mathrm{J} / \mathrm{mol} \cdot \mathrm{K})$ of $\mathrm{HCN}, \mathrm{H}_{2} \mathrm{O}$ and $\mathrm{C}_{2} \mathrm{H}_{2}$ were used (Table 1). The data are given for standard pressure 1 atmosphere and absolute temperature $298.15 \mathrm{~K}$.

3. The experimental spectrum of $\mathrm{HCN}, \mathrm{H}_{2} \mathrm{O}$, and $\mathrm{C}_{2} \mathrm{H}_{2}$ molecules were used for comparison with theoretical calculated molecular vibrations.

Table 1. Thermodynamic characteristics of $\mathrm{HCN}, \mathrm{H}_{2} \mathrm{O}$ and $\mathrm{C}_{2} \mathrm{H}_{2}$ molecules [4].

\begin{tabular}{|lccccc|}
\hline Molecule & & Structure & $\boldsymbol{\Delta}_{\mathbf{f}}^{\mathbf{0}}, \mathbf{k J} / \mathbf{m o l}$ & $\Delta \mathbf{H}_{\mathbf{f}}^{\mathbf{0}}, \mathbf{k J} / \mathbf{m o l}$ & $\mathbf{S}^{\mathbf{0}}, \mathbf{J} / \mathbf{m o l} \cdot \mathbf{K}$ \\
\hline Hydrogen cyanide $(\mathrm{HCN})$ & $\mathrm{H}-\mathrm{C} \equiv \mathrm{N}$ & 407.5 & 437.6 & 202.6 \\
\hline Water & $\left(\mathrm{H}_{2} \mathrm{O}\right)$ & $\mathrm{H}-\mathrm{O}-\mathrm{H}$ & -237.14 & -285.83 & 69.95 \\
\hline Acetylene & $\left(\mathrm{C}_{2} \mathrm{H}_{2}\right)$ & $\mathrm{H}-\mathrm{C}=\mathrm{C}-\mathrm{H}$ & 210.7 & 226.88 & 201 \\
\hline
\end{tabular}

\section{RESULTS}

1. A. Hydrogen Cyanide molecule (theoretical data)

The HCN molecule is linear with fundamental frequencies: $v_{2}=712 \mathrm{~cm}^{-1}, v_{3}=3289 \mathrm{~cm}^{-1}$ and $v_{1}=2100 \mathrm{~cm}^{-1}$ [5]. The latter frequency (band
1) has not been observed directly since the band associated with it is of extremely low intensity- Figure 2. It can be seen that the frequency about $1400 \mathrm{~cm}^{-1}$, which is located between $712 \mathrm{~cm}^{-1}$ and $3289 \mathrm{~cm}^{-1}$ is absent from the theoretical data.

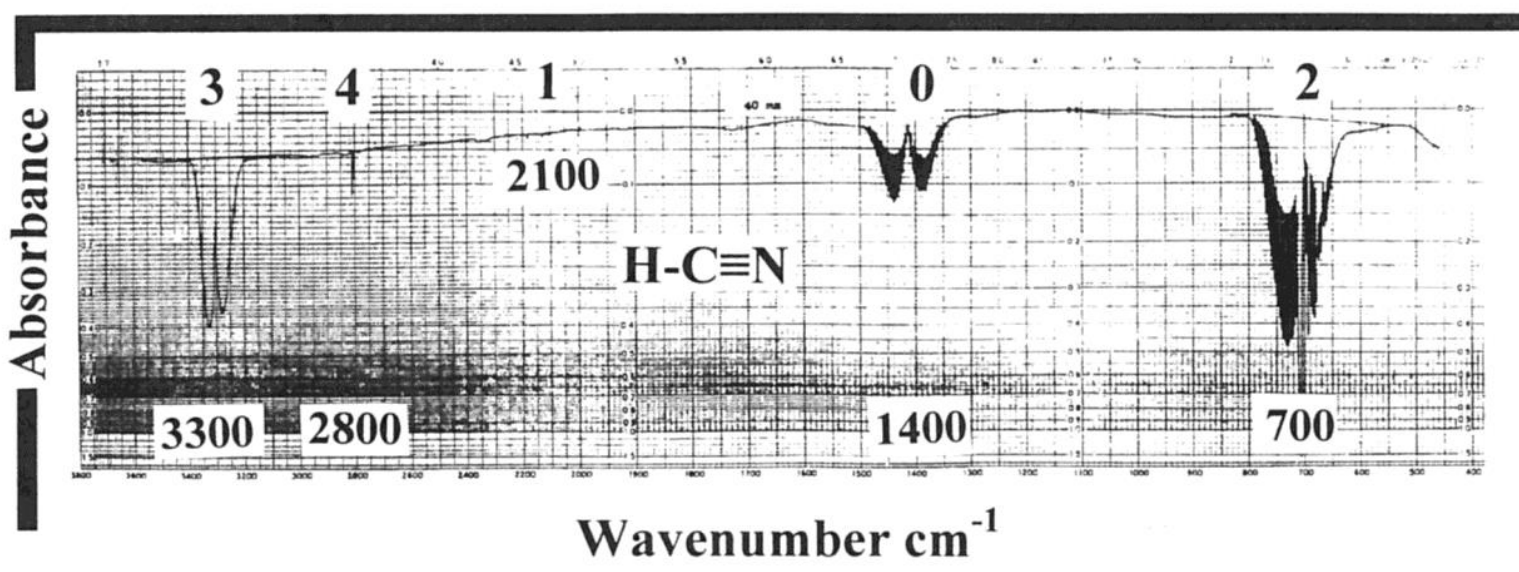

Figure 2. An original IR spectrum of Hydrogen Cyanide HCN [5].

B. Calculation of molecular vibrations of HCN by classical method. The calculation of vibrational modes of the $\mathrm{C}-\mathrm{H}$ and $\mathrm{C} \equiv \mathrm{N}$ bond gives the frequencies $3023 \mathrm{~cm}^{-1}$ and $1983 \mathrm{~cm}^{-1}$ respectively. It can be seen that these theoretical calculated frequencies do not fully coincide with the experimental frequencies from the absorption spectrum of HCN. For example, the calculated frequency of $1983 \mathrm{~cm}^{-1}$ is nearest to $v_{1}=2100 \mathrm{~cm}^{-1}$ and the calculated frequency of $3023 \mathrm{~cm}^{-1}$ is near to $v_{3}=3289$ $\mathrm{cm}^{-1}$. However, the theoretical calculation can't predict the frequency at $712 \mathrm{~cm}^{-1}, 1400 \mathrm{~cm}^{-1}$ and $2800 \mathrm{~cm}^{-1}$ which are present in the spectrum of the HCN molecule.

In these calculations it was used: force constants $\mathrm{k}=5 \times 10^{5}$ dyne $/ \mathrm{cm}$ for 'single bond' $\left(\mathrm{C}-\mathrm{H}\right.$ bond) and force constant $\mathrm{k}=15 \times 10^{5}$ dyne/cm for 'triple bond' ( $\mathrm{C} \equiv \mathrm{N}$ bond). The mass of $\mathrm{m}_{\mathrm{H}}, \mathrm{m}_{\mathrm{C}}$ and $\mathrm{m}_{\mathrm{N}}$ were calculated in 'grams' by relations: $\mathrm{m}_{\mathrm{H}}=1 / 6.02 \times 10^{23}=$ $0.166 \times 10^{-23} \mathrm{~g}, \mathrm{~m}_{\mathrm{C}}=12 / 6.02 \times 10^{23}=1.99 \times 10^{-23} \mathrm{~g}$ and $\mathrm{m}_{\mathrm{N}}=14 / 6.02 \times 10^{23}=2.33 \times 10^{-23} \mathrm{~g}$.

C. Calculation of molecular vibrations of HCN by new thermodynamic method. The calculation of $T_{\mathrm{G}}=\Delta \mathrm{G} / \Delta \mathrm{S}$ 'apparent' temperature was based on Gibbs free energy $\Delta \mathrm{G}_{\mathrm{f}}^{0}=407.5 \mathrm{~kJ} / \mathrm{mol}$ and entropy of $\mathrm{HCN}$ molecule $\mathrm{S}^{0}=202.6 \mathrm{~J} / \mathrm{mol} \cdot \mathrm{K}$ [3]. The calculated 'apparent' temperature, corresponding to Gibbs free energy is: $\mathrm{T}_{\mathrm{G}}=\Delta \mathrm{G}_{\mathrm{f}}{ }^{0} / \mathrm{S}^{0}=407.5 \times 10^{3} / 202.6=2.011 \times 10^{3} \mathrm{~K}$.

The corresponding frequency calculated by formula (15) is: $\nu^{0}{ }_{\mathrm{TD}}=1 / \lambda=\mathrm{kT}_{\mathrm{G}} / \mathrm{ch}\left(\mathrm{cm}^{-1}\right)=1396.3$ $\mathrm{cm}^{-1}$. The abbreviation ' $v^{0} \mathrm{TD}$ ' is used to indicate that the frequency is calculated by the thermodynamic method. The calculated frequency $v_{\mathrm{TD}}^{0}=1396.3 \mathrm{~cm}^{-1}$ correspond to 
$1400 \mathrm{~cm}^{-1}$ band on IR spectrum of HCN. From $v_{\mathrm{TD}}^{0}$ frequency it can receive the frequencies of
ATANASOV A. T. the other modes in IR spectra of $\mathrm{HCN}$ on Figure 2 (Table 2).

Table 2. Calculation of vibrational modes of $H C N$ in $\mathrm{cm}^{-1}$

\begin{tabular}{|l|}
\hline $1396.3 \mathrm{~cm}^{-1} \rightarrow 1400 \mathrm{~cm}^{-1}(0 \mathrm{band})$ \\
\hline $1396.3 \mathrm{~cm}^{-1} \times 1.5=2094.5 \mathrm{~cm}^{-1} \rightarrow 2100 \mathrm{~cm}^{-1}(1$ band $)$ \\
\hline $1396.3 \mathrm{~cm}^{-1}: 2.0=698.15 \mathrm{~cm}^{-1} \rightarrow 712 \mathrm{~cm}^{-1}(2$ band $)$ \\
\hline $1396.3 \mathrm{~cm}^{-1} \times 2.0=2792.6 \mathrm{~cm}^{-1} \rightarrow 2800 \mathrm{~cm}^{-1}(4$ band \\
\hline $1396.3 \mathrm{~cm}^{-1} \times 2.5=3490 \mathrm{~cm}^{-1} \rightarrow 3200-3400 \mathrm{~cm}^{-1}(3$ band $)$ \\
\hline
\end{tabular}

From Table $\mathbf{2}$ is seen that the derivative modes can be obtained from the main mode $v_{\text {TD }}^{0}$ $=1396.3 \mathrm{~cm}^{-1}$ as multiple of $1.5,2.0,2.5$, $3.0 \ldots$, and so on.

\section{Water molecule.}

A. Calculation of molecular vibrations of water by classical method.

An original water infrared spectrum is shown on Figure 3.

The calculation of mode of the $\mathrm{O}-\mathrm{H}$ bond gives the frequency of $2994.16 \mathrm{~cm}^{-1}$. From Figure 3 it can be seen that these theoretical calculated frequency do not coincide with the experimental frequencies on the IR spectrum of $\mathrm{H}_{2} \mathrm{O}$.

In these calculations it was used: force constants $\mathrm{k}=5 \times 10^{5}$ dyne/cm for 'single bond' (O-H bond). These mass of $\mathrm{m}_{\mathrm{H}}$ and $\mathrm{m}_{\mathrm{O}}$ were calculated in 'grams' by relations: $\mathrm{m}_{\mathrm{H}}$ $=1 / 6.02 \times 10^{23}=0.166 \times 10^{-23} \mathrm{~g}$ and $\mathrm{m}_{\mathrm{O}}$ $=16 / 6.02 \times 10^{23}=2.6578 \times 10^{-23} \mathrm{~g}$.

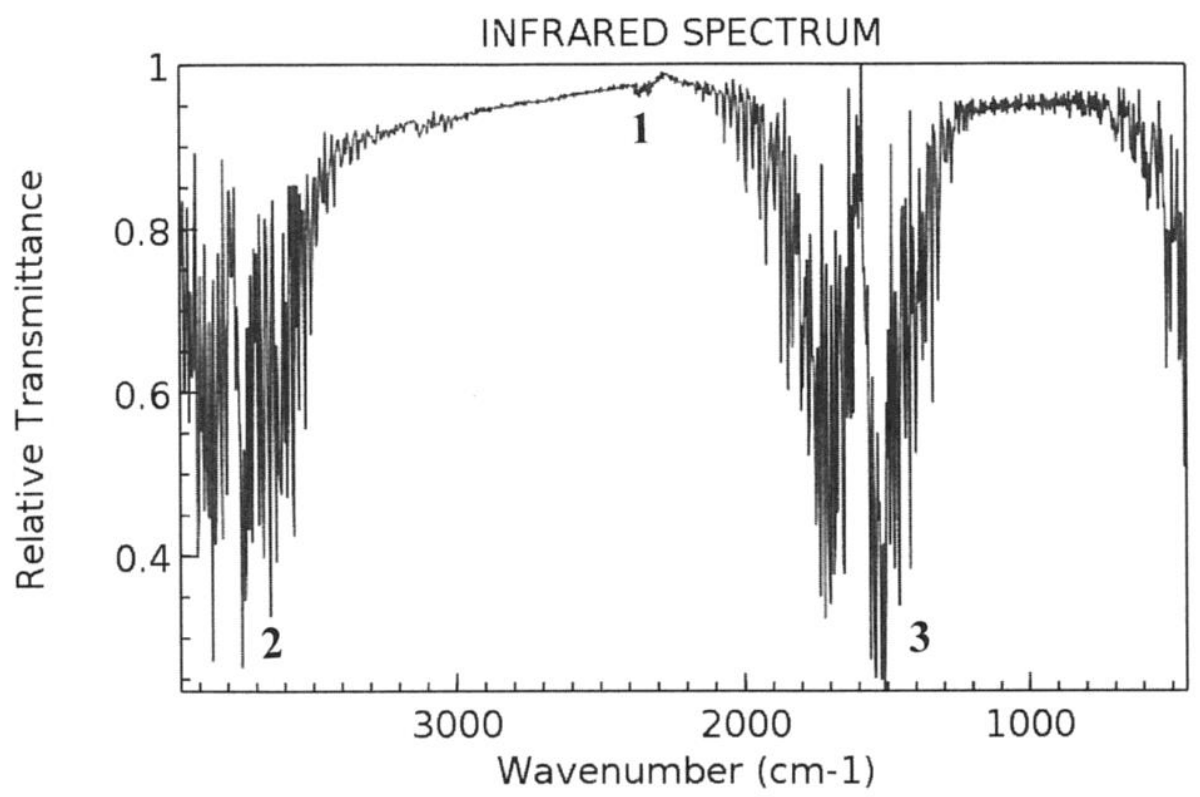

Figure 3. Infrared liquid $\mathrm{H}_{2} \mathrm{O}$ spectrum [6].

B. Calculation of molecular vibration of water by thermodynamic method.

The calculation of $T_{\mathrm{G}}=\Delta \mathrm{G} / \Delta \mathrm{S}$ 'apparent' temperature was based on Gibbs free energy $\Delta \mathrm{G}_{\mathrm{f}}^{0}=-237.14 \mathrm{~kJ} / \mathrm{mol}$ and entropy of $\mathrm{H}_{2} \mathrm{O}$ molecule $S^{0}=69.95 \mathrm{~J} / \mathrm{mol} \cdot \mathrm{K}$ [3].

Because the negative values of $\Delta \mathrm{G}_{\mathrm{f}}^{0}$, the 'apparent' temperature corresponding to Gibbs free energy must be represented as the absolute value of the ratio: $T_{G}=\left|\Delta G_{f}^{0} / S^{0}\right|$ $=237.14 \times 10^{3} / 69.95=3.39 \times 10^{3} \mathrm{~K}$. The corresponding stretching frequency calculated by formula (15) is: $v_{\mathrm{TD}}^{0}=1 / \lambda=\mathrm{kT}_{\mathrm{G}} / \mathrm{ch}\left(\mathrm{cm}^{-1}\right)=2353.3$ $\mathrm{cm}^{-1}$.
The calculated basic frequency of $v^{1} \mathrm{TD}=2353.3$ $\mathrm{cm}^{-1}$ correspond to small middle band (band 1) on IR spectrum of $\mathrm{H}_{2} \mathrm{O}$ (Fig.3). From $v^{1}$ TD frequency it can receive the frequency of other modes i.e: $v_{\mathrm{TD}}^{1} \times 1.5=3529.95 \mathrm{~cm}^{-1}$ (band 2) and $v^{1}{ }_{\mathrm{TD}}: 1.5=1568 \mathrm{~cm}^{-1}$ (band 3). The calculation of $\mathrm{T}_{\mathrm{H}}=\left|\Delta \mathrm{H}_{\mathrm{f}}^{0} / \mathrm{S}^{0}\right|$ based on enthalpy $\Delta \mathrm{H}_{\mathrm{f}}^{0}=-285.83 \mathrm{~kJ} / \mathrm{mol}$ and entropy $\mathrm{S}^{0}=69.95$ $\mathrm{J} / \mathrm{mol} \cdot \mathrm{K}$ of $\mathrm{H}_{2} \mathrm{O}$ molecule [3] gives frequency of $2836.39 \mathrm{~cm}^{-1}$. This frequency does not correspond to any band on IR spectrum of water. 


\section{Acetylene.}

A. Calculation of molecular vibration of acetylene by classical method. An original spectrum of acetylene is shown on Figure 4.

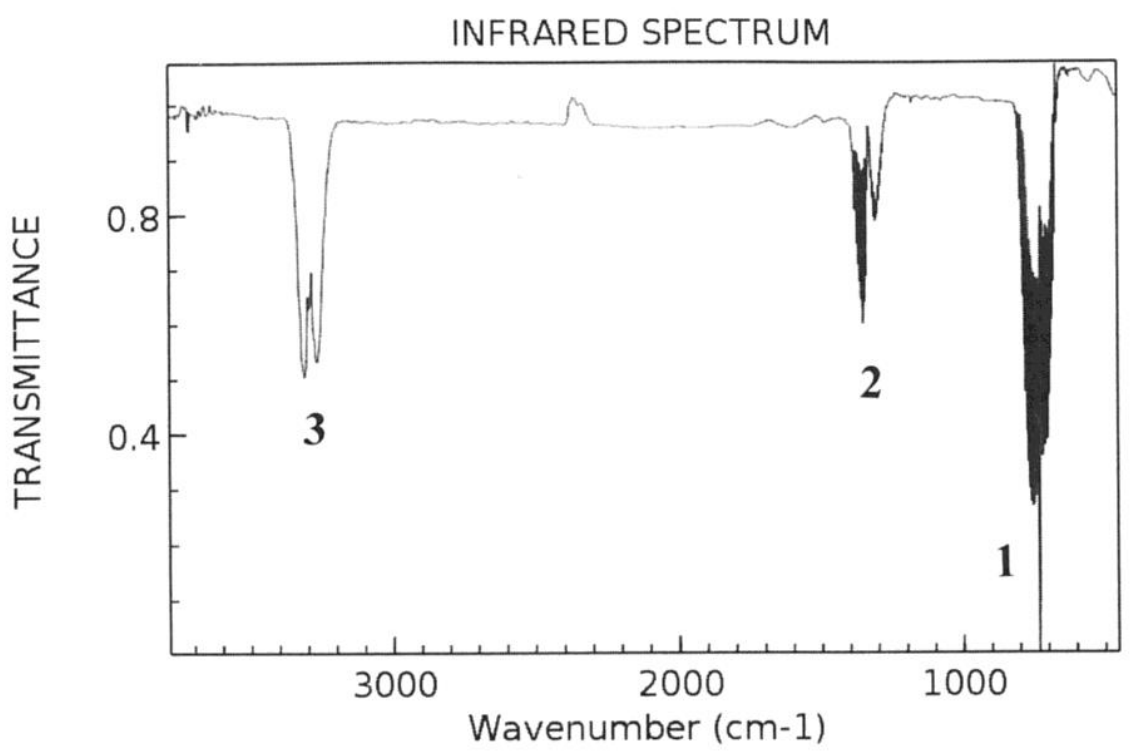

Figure 4. Acetylene Infrared gas Spectrum [6].

The calculation of modes of the $\mathrm{C}-\mathrm{H}$ and $\mathrm{C} \equiv \mathrm{C}$ bonds gives the frequency of $3023 \mathrm{~cm}^{-1}$ and $5251.6 \mathrm{~cm}^{-1}$ respectively. It can be seen that these theoretical calculated frequencies do not coincide with the experimental frequencies on the IR spectrum of $\mathrm{C}_{2} \mathrm{H}_{2}$.

In these calculations it was used: force constants $\mathrm{k}=5 \times 10^{5}$ dyne $/ \mathrm{cm}$ for 'single bond' (C-H) and force constant $\mathrm{k}=15 \times 10^{5}$ dyne $/ \mathrm{cm}$ for 'triple bond' $(\mathrm{C} \equiv \mathrm{C})$. The mass $\mathrm{m}_{\mathrm{H}}$ and $\mathrm{m}_{\mathrm{C}}$ were calculated in 'grams' by relations: $\mathrm{m}_{\mathrm{H}}$ $=1 / 6.02 \times 10^{23}=0.166 \times 10^{-23} \mathrm{~g}$ and $\mathrm{m}_{\mathrm{C}}$ $=12 / 6.02 \times 10^{23}=1.99 \times 10^{-23} \mathrm{~g}$.

B. Calculation of molecular vibration of acetylene by thermodynamic method.

The calculation of $T_{G}=\Delta G / \Delta S$ 'apparent' temperature was based on Gibbs free energy $\Delta \mathrm{G}_{\mathrm{f}}^{0}=210.7 \mathrm{~kJ} / \mathrm{mol}$ and entropy of $\mathrm{C}_{2} \mathrm{H}_{2}$ molecule $S^{0}=201 \mathrm{~J} / \mathrm{mol} \cdot \mathrm{K}$ [4].

The 'apparent' temperature was estimated to be: $\mathrm{T}_{\mathrm{G}}=\Delta \mathrm{G}_{\mathrm{f}}^{0} / \mathrm{S}^{0}=210.7 \times 10^{3} / 201=1.048 \times 10^{3} \mathrm{~K}$. The corresponding frequency calculated by formula (15) is: $v_{\mathrm{TD}}^{1}=1 / \lambda=\mathrm{kT}_{\mathrm{G}} / \mathrm{ch}\left(\mathrm{cm}^{-1}\right)=720$ $\mathrm{cm}^{-1}$. The calculated frequency $v_{\mathrm{TD}}^{1}=720 \mathrm{~cm}^{-1}$ correspond to biggest band (band 1) on IR spectrum of acetylene (Fig.4). From $v^{1}$ TD frequency it can receive frequencies of the others modes i.e: $v_{\text {TD }}^{1} \times 20=1440 \mathrm{~cm}^{-1}$ (band 2) and $v_{\mathrm{TD}}^{1} \times 4.5=3240 \mathrm{~cm}^{-1}$ (band 3). The calculation of $\mathrm{T}_{\mathrm{H}}=\Delta \mathrm{H}_{\mathrm{f}}^{0} / \mathrm{S}^{0}$ based on enthalpy $\Delta \mathrm{H}_{\mathrm{f}}{ }^{0}=226.88 \mathrm{~kJ} / \mathrm{mol}$ and entropy $\mathrm{S}^{0}=201$ $\mathrm{J} / \mathrm{mol} \cdot \mathrm{K}$ of acetylene molecule [3] gives frequency of $784.33 \mathrm{~cm}^{-1}$. This frequency is near to $720 \mathrm{~cm}^{-1}$ and correspond too with band 1 on IR spectrum of acetylene. This result due to the approximate values of $\Delta \mathrm{G}_{\mathrm{f}}^{0}=210.7$ $\mathrm{kJ} / \mathrm{mol}$ and of $\Delta \mathrm{H}_{\mathrm{f}}^{0}=226.88 \mathrm{~kJ} / \mathrm{mol}$.

\section{DISCUSSION}

The study on IR spectra of over 50 molecules (unpublished data) showed the calculating 'apparent' temperatures and corresponding frequency are more relevant to experimental IR spectra, when are calculated on the base of $\Delta \mathrm{G}_{\mathrm{f}}^{0} / \mathrm{S}^{0}$ than $\Delta \mathrm{H}_{\mathrm{f}}^{0} / \mathrm{S}^{0}$ ratio. For example: in the case of Hydrogen cyanide the calculation of $\mathrm{T}_{\mathrm{H}}=\Delta \mathrm{H} / \Delta \mathrm{S}$, based on enthalpy $\Delta \mathrm{H}_{\mathrm{f}}^{0}=437.6$ $\mathrm{kJ} / \mathrm{mol}$ and entropy $\mathrm{S}^{0}=202.6 \mathrm{~J} / \mathrm{mol} \cdot \mathrm{K}$ of $\mathrm{HCN}$ molecule gives frequency of $1499.34 \mathrm{~cm}^{-1}$. This frequency closer to $1500 \mathrm{~cm}^{-1}$ than to $1400 \mathrm{~cm}^{-1}$ and falls outside the peak 2 on Fig.2. In the case of $\mathrm{H}_{2} \mathrm{O}$ molecule the calculated by classical method frequency $2994.16 \mathrm{~cm}^{-1}$ do not correspond to any band on IR water spectrum. The same is situation with acetylene molecule. This shows that the infrared spectra related more to Gibbs free energy, rather than enthalpy of the molecular formation. In many cases the calculated basic frequencies $\left(v_{\mathrm{TD}}\right)$ fall in far-infrared region (below $400 \mathrm{~cm}^{-1}$ ), but its multiple mods (who overlap with the actual absorption frequencies) are located in midinfrared spectral region. The different multiple mods can be obtained from the basic frequencies $v_{\mathrm{TD}}$. For this purpose the basic frequency must be represented as multiple of $1.5,2.0,2.5,3.0 \ldots$, and so on. 
From the presented results, it can be seen that the calculated by thermodynamic method frequencies coincide with the experimental absorption frequencies on the infrared spectrum of the studied molecules. The proposed method gives possibility for theoretical prediction of potential absorption frequencies (mods) in the infrared spectrum of the unknown molecules. A similar relationship between the vibrational assignment and the thermodynamic properties of some simple molecules were sought by other authors too. A similar relationship between the vibrational assignment and the thermodynamic properties of some simple molecules were sought previously by other authors too $[7,8]$. The proposed new method may be a good complement to recently existing methods for spectral analyses.

\section{REFERENCES}

1. Pecsok, R.L.; Shields L.D. Modern Methods of Chemical Analysis, Wiley, New York, 1968.
ATANASOV A. T.

2. Daiev, Ch.; Belchev, S.; Shishkova, L.; Harizanov, Jr. et. all. Manual on physical methods for analysis and investigation of inorganic objects, Second Ed., Sofia (Bulgaria), 1992.

3. Metzler, D.E., Biochemistry. Academic Press Inc., Iowa State University, 1977.

4. Dean J.A., Lange's Handbook of Chemistry, $12^{\text {th }}$ ed., McGraw-Hill: New York, pp.9-4-9-94, 1979

5. Choi, K. N.; Barker, E.F., Infrared absorption of hydrogen cyanide. Phys. Rev., 42, 777, 1932.

6. NIST Chemistry Webbook (http://webbook.nist.gov).

7. McClellan, A.L.; Pimentel, G.C. Vibrational assignment and thermodynamic properties of Naphthalene. The Journal of Chemical Physics 23, 245, 1955.

8. Claassen H.H.; Weinstock B.; Malm J.G. Vibrational spectra and thermodynamic properties of $\mathrm{CIF}_{3}$ and $\mathrm{BrF}_{3}$. The Journal of Chemical Physics 28, 285,1958. 